\title{
Basel violations, volatility model variants and value at risk: Optimization of performance deviations in banks
}

\author{
Shahid Anjum ${ }^{1 * *}$ • Naveeda Qaseem² \\ ${ }^{1}$ Universiti Teknologi Brunei, Brunei Darussalam \\ ${ }^{2}$ University of Westminster, United Kingdom
}

Received: 26 October 2020

Revised: 12 February 2021

Accepted: 14 February 2021

\begin{abstract}
Basel penalties originate from VaR violations, based on the type of variance models and the estimation of VaR thresholds employed by the bank, which leads to excess regulatory capital charge held and can affect banks' risk taking ability and thus its profitability. Different approaches are used to evaluate the performance of variance models and forecasts of the VaR thresholds i.e. hypothesis tests, back-testing procedures and Basel Accord regulatory calculations for penalty zones. A multi-criteria performance measure named as analytical hierarchy process has been introduced in this study. The approach helps in evaluating and selection of the optimal internal model based on performance evaluation techniques objectively which, in turn, may help in the selection of best volatility internal model for reduction in the $\mathrm{VaR}$ violations and thus leaving more capital in the hands of the banks for profitable ventures.
\end{abstract}

Keywords: volatility models; value at risk estimation and performance measures; multivariate techniques; multi-criteria decision making

JEL Classification Codes: G21, K23, M16, N20, O16

\section{Introduction}

Volatility is the focus of market risk measurement, management and reporting exercises. Measuring the variance or volatility of the market portfolio is at the heart of measuring VaR threshold for the capital charge of market risk (Bhandari; 2010; Dardac et el.; 2011 \& Mehta et el.; 2012) and thus banks' compliance with Basel regulations (Anjum; 2018). Under Basel II.V and III, banks are allowed to use insurance risk measures (IRM) approach which make use of an internal VaR model (IBM; 2011 and Pwc. 2012).

Each bank must, on a daily basis, meet the level of market risk capital requirement expressed as the higher of its previous day's VaR number and an average of the daily VaR measures on each of the preceding sixty business days, multiplied by a multiplication factor which depends on the back-testing performance of the VaR model (Sharma; 2011 \& Stretton et el.; 2011).

\footnotetext{
* Corresponding author. E-mail: anjumsw@ hotmail.com.
}

Citation: Anjum, S., and Qaseem, N. (2021) Nexus between green bonds, financial, and environmental indicators, Economics and Business Letters, 10(3), 240-248.

DOI: 10.17811/ebl.10.3.2021.240-248 
Various performance measures are used in order to compare different variance models and VaR estimates which can be broadly categorized as back-testing procedures, hypothesis tests and regulatory calculations (koh et el.; 2012 \& Rowe et el.; 2011). Besides, McAleer et. el. (2006) has used linear regression approach to assess the performance of VaR measure. Although VaR can be compared for individual models, multi-criteria analysis may, however, provide precise assessment.

This study presents a novel approach in using multi-criteria based performance measures for the comparison of single index volatility models (SIVM) and portfolio volatility models (PVM) based on analytical hierarchy process (AHP). It has been divided into five sections: introduction in section 1, literature review in section 2, data description and methodology in section 3, results and analysis in section 4 and finally conclusion is presented in section 5 .

\section{Literature review}

Broad spectrum of banking risk and related approaches are found in literature. Using nonparametric and Copula approaches, Huynh et el. (2020) has suggested that risks in portfolio stock returns of Vietnamese banks because of contagion aspects may be diverted through diversification. Various studies have also used the magnitude of the average violations (AV) (arising from using different models to forecast the VaR threshold), the size of the average capital charge (ACC) and average deviation (AD) of VaR Violations (ADVV) in order to compare various volatility models for forecasting VaR threshold. Some have also derived likelihood ratio (LR) tests of unconditional coverage, serial independence and conditional coverage which have been adapted to evaluate VaR threshold forecasts (McAleer et. el.; 2006).

Various performance measures and approaches are used in literature. Le et el. (2020) have shown that optimal ratios, reflecting Basel-III's minimum common equity ratio and estimated using fully-modified and dynamics OLS models on UK and Australian banking data from 2000 to 2019 , perform better than stricter capital ratio does not to improve bank profitability and efficiency. Ngo et el. (2018) has incorporated credit risk into the estimation of estimated efficiency scores by incorporating credit risk into the applying directional distance function and semi-parametric framework on panel data from 2000 to 2015 and has found no evidence of impact of technological progress on ASEAN banks is found. Sugiarto et el. (2020) has found that expected credit loss (ECL) model in IFRS 9 (i.e. PSAK 71) in calculating impairment loss allowance (CKPN), using integration of Markov chain, exponential smoothing, time series analysis of behavioural inherent trends of probability of default, tail conditional expectation and Monte Carlo simulations for Indonesian banks is more prudent than the implementation of impairment in financial instruments in incurred loss model of PSAK 55. Discussions can also be found about: risks in Shariah banks in Anjum (2013a, 2015a\&b), banking risks and operating efficiency in Shamim (2015), technology diffusion in Japanese banks in Shamim (2013), scenario based cases in Chaudhary et. el. (1996), systematic risk outliers in Anjum (2014a), VaR violations in Anjum (2014c) and ranking based on fuzzy scales in Anjum (2014e) and clouds computing in Anjum (2017a\&b).

VaR calculations for Performance measures as well as comparison of various volatility models for variance-covariance matrix require various steps. Performance measures can be broadly categorized into regulatory test measures (RTM) and hypothesis test measures (HTM) of unconditional and conditional coverage (Sharma; 2012). McAleer et. el. (2006) and Sharma (2012) have used three likelihood ratio based hypothesis test measures called unconditional coverage test (UCT), the serial independence of violations test (SIVT) and the conditional coverage test (CCT) whereas the later has also used regulatory back test (RBT) and the former has also used a linear regression approach (LRA). In LRA, volatility forecasts are regressed on the realized volatility, in order to compare the forecasting performance of various SIVMs 
and PVMs where equal portfolio weights which are constant over time have been assumed for forecasting period from April 1998 to Nov. 2004 for Datastream datasets of S\&P500, FITSE100, CAC40 and SMI indexes to forecast the 1-day ahead conditional correlations, conditional variances and VaR thresholds.

The SIVT is the LR statistic for the null hypothesis of serial independence against the alternative of first-order Markov dependence. LR test for conditional coverage test (a joint hypothesis test of unconditional coverage and independence of exceptions) is the sum of the unconditional coverage LR statistic and the independence LR statistic. Furthermore, the Basel Accord imposes penalties in the form of a higher multiplicative factor $\mathrm{k}$ on banks which use models that lead to a greater number of violations than would reasonably be expected for confidence level of $1 \%$. The other two performance measures, i.e. the ACC and ADVV are obvious ones. The empirical results based on various criteria offer mixed evidence on the relative performance of the VaR threshold forecasts produced by the SIVMs and PVMs. Results for these three tests for SIVMs and PVMs have been used to derive VaR.

Based on LRA, conditional volatility models (CVM) estimated using a t-distribution tend to display marginally superior forecasts, the only exception being the portfolio CCC model. In all cases, the portfolio models outperform the SIVMs based on $\mathrm{R}^{2}$, which suggests that the PVMs leads to superior forecasts of the conditional variance of the PVMs compared with their single index (SI) counterparts. In short, the existing literature applies various while methods to measure the risks in banks, banking tock returns or performance measures in silos, however, it falls short of providing a multi-criteria based performance measures for the comparison of various SIVM and PVM in order to avoid BASEL penalties.

\section{Data description and methodology}

The current study argues that any inference based on any one of the above mentioned seven criteria (7CRIT) described in McAleer et. el. (2006) may be overly simplistic. A new approach uses AHP in order to rank the seven criteria. These 7CRIT are named as UCT, SIVT, CCT, mean number of $\mathrm{VaR}$ violations (NOV or ' $\mathrm{k}$ '), mean daily capital charge (MDCC), average deviation of VaR violations (ADVV) and $\mathrm{R}^{2}$ as measure of forecasting Performance (MFP) for the back-testing LR based on the method used by McAleer et. el. (2006). The hierarchy of various criteria is shown in Figure 1.

The calculation of relative scores, based on the practical importance of each criterion, uses AHP's pair-wise comparison matrix (PWCM) (Anjum 2013b \& 2014b). Results for normalized PWCM, rounded to three decimals for weights, are shown in Table 1. By solving the eigenvector equation, the maximum eigenvalue $\lambda_{\max }$, the relative importance of each criterion is obtained (Bonissone; 1988) whose incommensurate values for MDCC, NOV, ADVV, MFP, CCT, UCT and SIVT are 0.356, 0.246, 0.185, 0.097, 0.056, 0.038 and 0.022 respectively. The value of $\lambda_{\max }$ is the average of consistency vector. Our consistency index (i.e. $\left.C I=\left(\lambda_{\max }-n\right) /(n-1) \& n=7\right)$ is 0.0995 . Value of random consistency ratio (RI) for a matrix size of $7 \times 7$ is 1.32 from the table. Finally, we have calculated consistency ratio i.e. $C R=C I / R I$

Figure 1. Various Criteria and Sub-criteria used to Rank various VaR Measures.

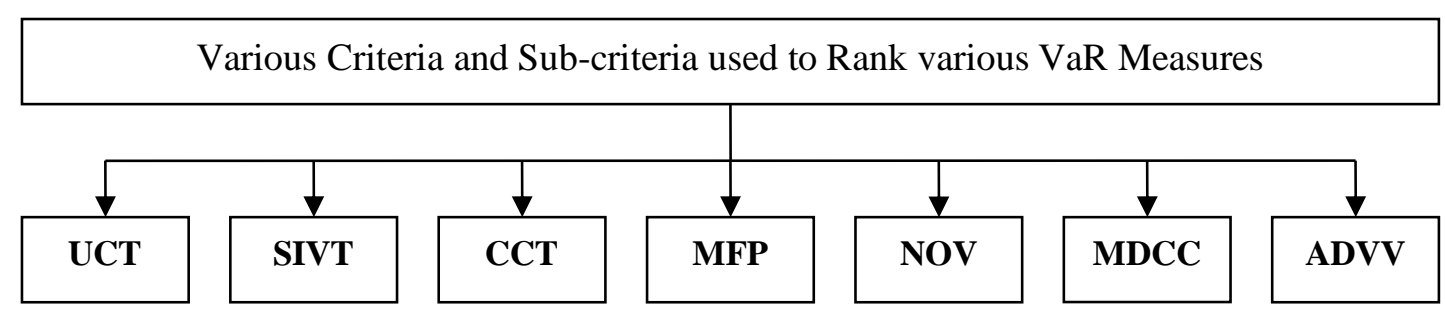

Note: The descriptions of the Abbreviations used in this diagram have been provided in the text. 
Table 1. Normalized Pair-wise Weight Matrix.

\begin{tabular}{|c|c|c|c|c|c|c|c|}
\hline & $\overline{M D C C}$ & NOV & $\overline{A D V V}$ & MFP & $\overline{C C T}$ & $\overline{U C T}$ & $\overline{\text { SIT }}$ \\
\hline$M D C C$ & 0.7 & 2.14 & 3.37 & 0.014 & 0 & 1.35 & 3.54 \\
\hline NOV & 4.54 & 2.77 & 4.06 & 0.124 & 3.66 & 4.53 & 4.13 \\
\hline$A D V V$ & 5.49 & 0 & 3.68 & 0.022 & 0.27 & 1.64 & 0 \\
\hline$M F P$ & 4.88 & 2.06 & 3.68 & 0.022 & 0.27 & 4.09 & 3.44 \\
\hline$C C T$ & 5.76 & 2.22 & 4.03 & 0.122 & 3.59 & 4.17 & 3.63 \\
\hline$U C T$ & 4.7 & 3.8 & 4.12 & 0.125 & 3.69 & 4.05 & 4.4 \\
\hline SIT & 5.76 & 2.22 & 4.03 & 0.168 & 5.12 & 4.21 & 3.63 \\
\hline Priority Vector & 3.6 & 3.88 & 3.8 & 0.175 & 5.36 & 3.88 & 4.37 \\
\hline
\end{tabular}

Note: Diagonal cells in the "original PWC matrix", with same order of seven criteria, carries the value of 1 while the entries in the other cells with row-column combinations of 1-2, 1-3, 1-4, 1-5, 1-6, 1-7, 2-3, 2-4, 2-5, 2-6, 2-7, 3-4, 3-5, 3-6, 3-7, 4-5, 4-6, 4-7, 5-6, 5-7 and 6-7 are 2, 3, 5, 7, 8, 9, 2, 4, 6, 7, $8,3,5,7,9,3,5,5,3,4$ and 4 . The entries in other cells are reciprocal to just mentioned non-diagonal entries.

Table 2. Basel Accord Penalty Zones (BAPZ).

\begin{tabular}{lrr}
\hline \hline Zone & NOV & Increase in ' $\boldsymbol{k}$ ' score \\
\hline Green & 0 to 4 & 0.00 \\
& 5 & 0.40 \\
Yellow & 6 & 0.50 \\
& 7 & 0.65 \\
& 8 & 0.75 \\
Red & 9 & 0.85 \\
\hline \hline
\end{tabular}

Note: (1) Number of violations is given for 250 business days. (2) NOV $\geq 10$ is $\mathrm{k}=1$ (Basel Regulation).

Figure 2. BAPZ based Disutility Function (BDF).

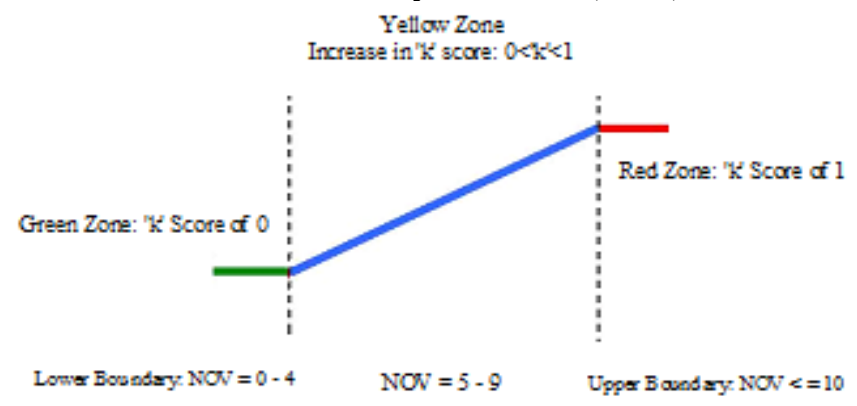

whose value was $7.54 \%$ and as it is below $10 \%$, our AHP matrix was consistent meaning that there was no issue of decision reversibility (Anjum 2014d).

Transformation of all the criteria to a range of 0 to 1 has been achieved by using Kramer (2008) style utility function based on 'k' penalty factor for NOV criteria (Table 2 and Figure 2).

If the NOV is less than or equal to 4, then value for $\mathrm{k}=0$ and if NOV exceed 9, then value for ' $k$ ' is 1 . Any NOV value between 4 to 10 can be solved by using MinMax function. This has been shown in Table 2 and Figure 2 entitled Basel Accord Penalty Zones (BAPZ) alongwith corresponding Disutility function showing that the more the NOV, the more the value for ' $\mathrm{k}$ ' thus adding more disutility to the bank because of increasing capital charges. The daily capital charge for the trading book $\left(\mathrm{C}_{t}\right)$ is given as the negative of regulatory factor $(\mathrm{p})$ (i.e. $3+\mathrm{k}$ ) times the greater of the previous day's VaR or the average VaR over the last 60 business days, where $\mathrm{k}$ is the Basel III penalty (McAleer; 2006). 
Table 3. Rules for Performance Evaluation Criteria.

\begin{tabular}{|c|c|c|c|}
\hline Criteria & Rule & Criteria & Rule \\
\hline $\operatorname{MFP}\left(\mathrm{R}^{2}\right)$ & Max value is better & CCT & $\begin{array}{l}\text { Higher Value is bad and a Value of over } 6 \\
\text { will fail the test }\end{array}$ \\
\hline MDCC & $\begin{array}{l}\text { Higher Value is } \\
\text { bad }\end{array}$ & UCT & $\begin{array}{l}\text { Higher Value is bad and a Value of over } \\
3.5 \text { will fail the test }\end{array}$ \\
\hline ADVV & $\begin{array}{l}\text { Higher Value is } \\
\mathrm{Bad}\end{array}$ & SIVT & $\begin{array}{l}\text { Higher Value is bad and a Value of over } 2 \\
\text { will fail the test }\end{array}$ \\
\hline
\end{tabular}

References: McAleer et el. (2006), Sharma (2012).

Table 4. Normalized Scores in \% of Single Index Volatility Models based on Individual Criteria and Combined Criteria (last Column).

\begin{tabular}{|c|c|c|c|c|c|c|c|c|c|}
\hline Name & $\begin{array}{r}\text { MDCC } \\
\text { based } \\
\text { Rank }\end{array}$ & $\begin{array}{r}\text { NOV } \\
\text { based } \\
\text { Rank }\end{array}$ & $\begin{array}{r}\text { ADVV } \\
\text { based } \\
\text { Rank }\end{array}$ & $\begin{array}{c}R^{2} \\
\text { Values }^{l} \\
\text { Single I }\end{array}$ & $\begin{array}{c}R^{2} \\
\text { based } \\
\text { Rank } \\
\text { dex Mo }\end{array}$ & $\begin{array}{c}C C T \\
\text { based } \\
\text { Rank } \\
\text { dels } \\
\end{array}$ & $\begin{array}{r}\text { UCT } \\
\text { based } \\
\text { Rank }\end{array}$ & $\begin{array}{r}\text { SIT } \\
\text { based } \\
\text { Rank }\end{array}$ & $\begin{array}{c}\text { NGS } \\
\text { Final } \\
\text { Rank }\end{array}$ \\
\hline Std. Normal & 0.7 & 2.14 & 3.37 & 0.014 & 0 & 1.35 & 3.54 & 1.48 & 1.76 \\
\hline Riskmetrics $^{\mathrm{TM}}$ & 4.54 & 2.77 & 4.06 & 0.124 & 3.66 & 4.53 & 4.13 & 4.1 & 3.87 \\
\hline $\mathrm{ARCH}$ & 5.49 & 0 & 3.68 & 0.022 & 0.27 & 1.64 & 0 & 4.15 & 2.71 \\
\hline $\mathrm{ARCH}-\mathrm{t}$ & 4.88 & 2.06 & 3.68 & 0.022 & 0.27 & 4.09 & 3.44 & 4.15 & 3.37 \\
\hline $\mathrm{CCC}$ & 5.76 & 2.22 & 4.03 & 0.122 & 3.59 & 4.17 & 3.63 & 4.1 & 4.05 \\
\hline CCC-t & 4.7 & 3.8 & 4.12 & 0.125 & 3.69 & 4.05 & 4.4 & 3.47 & 4.17 \\
\hline GJR & 5.76 & 2.22 & 4.03 & 0.168 & 5.12 & 4.21 & 3.63 & 4.14 & 4.18 \\
\hline GJR-t & 3.6 & 3.88 & 3.8 & 0.175 & 5.36 & 3.88 & 4.37 & 3.33 & 3.9 \\
\hline EGARCH & 5.82 & 2.46 & 4.43 & 0.168 & 5.12 & 4.36 & 3.87 & 4.12 & 4.36 \\
\hline EGARCH-t & 4.64 & 4.2 & 3.84 & 0.196 & 6.06 & 2.56 & 4.14 & 2.22 & 4.26 \\
\hline PGARCH & 5.91 & 2.54 & 4.68 & 0.177 & 5.42 & 4.4 & 3.94 & 4.11 & 4.49 \\
\hline PGARCH-t & 4.69 & 4.2 & 3.93 & 0.193 & 5.96 & 2.56 & 4.14 & 2.22 & 4.29 \\
\hline
\end{tabular}

Note: Footnote (1): $\mathrm{R}^{2}$ Values are from McAleer et. el. (2006).

The multiplicative factor $\mathrm{p}$ is set by the local regulators, but must not be lower than 3 . The regulatory factor (p) can range from a minimum value of 3.0 to an addition of a penalty based on back testing performance of the VaR model for market risk. The rest of the 6CRIT i.e. UCT, SIVT, CCT, MDCC, ADVV and MFP have been brought within the scale of 0 to 1 by directly using the MinMax function on the realized values.

The rules for criteria UCT, SIVT, CCT, NOV, MDCC, ADVV and MFP for the back-testing linear regression based method may be stated as that less value of NOV is preferred over the higher value and for any criteria or sub-criteria, MinMax will make the higher scores preferable over the low scores (inverse values have been inverted to make all the values as per this rule). The rules for the other six criteria and the scoring method used have been provided in Table 3.

Moreover, we have calculated the numerical score for each criteria of the univariate and multivariate variance models by multiplying the AHP weights with its MinMax based score of each criterion. These results have been shown in table 4 and table 5. The most common aggregation method is linear weighted addition which is applicable if all the criteria are in commensurate units (Al-Harbi et el.; 2001) as are in our case. In this way we have obtained the normalized scores for both single index models and portfolio models as are shown in last column of the Table 4 and Table 5. 


\section{Results and analysis}

Based on the UCT, with the exception of Riskmetrics ${ }^{\mathrm{TM}}$ and EGARCH, all the SVIMs, which assume normality, has failed i.e. they lead to a significantly greater number of violations than expected. The SIVMs estimated under the assumption that the returns follow a t-distribution performed far better, with the ARCH model being the only model to fail the UCT due to an excessive number of violations. Based on LRA, CVM estimated by McAleer (2006) using a t-distribution also tend to display marginally superior forecasts, the only exception being the portfolio CCC model. Virtually all of the normally distributed SIVMs are found to lead to a greater number of violations on the basis of the UCT. PVMs perform quite poorly, with ten of the sixteen models considered failing the UCT. It is worth noting that the PVMs fail the UCT and for a different reason i.e. because they lead to an insufficient number of violations. SIVMs lead to an excessive number of violations, while the PVMs have too few violations (McAleer et. el.; 2006). UCT rejects VaR models with either very high and very low coverage.

Based on the SIVT, a VaR method that does not adapt to high volatility conditions and produces clustered exceptions will fail SIVT (Sharma; 2012). As per the study by McAleer et. el. (2006), five SIVMs fail the SIVT and four of which assume that the returns follow a tdistribution. However, only two of the PVMs fail the serial independence test, both of which assume normality suggesting that serial independence test favors the portfolio model. Regarding CCT, eight of the twelve SIVMs fail it and eight of the sixteen PVMs also fail it. Based on MDCC for SIVMs and PVMs, the worst performing models are the SIVMs and PVMs which are standardized normal, which would lead to average daily capital charges of $12.92 \%$ and $12.33 \%$ respectively.

Table 5. Normalized Scores in \% of Portfolio Volatility Models based on Individual Criteria and Combined Criteria in last Column.

\begin{tabular}{lrrrrrrrrr}
\hline \hline & $\begin{array}{r}\text { MDCC } \\
\text { based } \\
\text { Rank }\end{array}$ & $\begin{array}{r}\text { NOV } \\
\text { based } \\
\text { Rank }\end{array}$ & $\begin{array}{r}\text { ADVV } \\
\text { based } \\
\text { Rank }\end{array}$ & $\begin{array}{r}R^{2} \\
\text { Values }\end{array}$ & $\begin{array}{r}R^{2} \\
\text { based } \\
\text { Rank }\end{array}$ & $\begin{array}{r}\text { CCT } \\
\text { based } \\
\text { Rank }\end{array}$ & $\begin{array}{r}\text { UCT } \\
\text { based } \\
\text { Rank }\end{array}$ & $\begin{array}{r}\text { SIT } \\
\text { based } \\
\text { Rank }\end{array}$ & $\begin{array}{c}\text { NGS } \\
\text { Final } \\
\text { Rank }\end{array}$ \\
& & & & \multicolumn{7}{c}{ Portolio Models } & & & \\
\hline Std. Normal & 0 & 2.06 & 3.42 & 0.014 & 0 & 0.08 & 3.44 & 0.33 & 1.42 \\
Riskmetrics & 5.26 & 2.69 & 4.23 & 0.129 & 3.83 & 4.47 & 4.08 & 4.09 & 4.12 \\
ARCH & 4.52 & 3.41 & 3.73 & 0.021 & 0.23 & 4.77 & 4.43 & 4.13 & 3.71 \\
ARCH-t & 2.79 & 4.2 & 4.03 & 0.021 & 0.23 & 4.58 & 4.14 & 4.15 & 3.42 \\
CCC & 3.86 & 4.36 & 3.89 & 0.14 & 4.19 & 4.44 & 3.94 & 4.15 & 4.07 \\
CCC-t & 1.69 & 4.83 & 0 & 0.139 & 4.16 & 3.6 & 2.75 & 4.16 & 2.61 \\
GJR & 3.81 & 4.36 & 3.86 & 0.185 & 5.69 & 4.45 & 3.94 & 4.15 & 4.18 \\
GJR-t & 1.61 & 4.75 & 3.69 & 0.19 & 5.86 & 3.82 & 3.06 & 4.15 & 3.49 \\
EGARCH & 3.85 & 4.44 & 4.02 & 0.198 & 6.12 & 4.36 & 3.82 & 4.15 & 4.26 \\
EGARCH-t & 1.64 & 4.75 & 3.95 & 0.198 & 6.12 & 3.82 & 3.06 & 4.16 & 3.57 \\
PGARCH & 3.74 & 4.44 & 3.99 & 0.199 & 6.16 & 0 & 3.82 & 0 & 3.85 \\
PGARCH-t & 1.5 & 4.75 & 3.92 & 0.201 & 6.22 & 3.82 & 3.06 & 4.16 & 3.53 \\
VARMA-GARCH & 3.77 & 4.44 & 4.06 & 0.146 & 4.39 & 4.36 & 3.82 & 4.15 & 4.11 \\
VARMA- & & & & & & & & & \\
GARCH-t & 1.53 & 4.83 & 0.79 & 0.133 & 3.96 & 3.6 & 2.75 & 4.16 & 2.71 \\
PS-GARCH & 2.65 & 4.36 & 4.11 & 0.136 & 4.06 & 4.45 & 3.94 & 4.15 & 3.73 \\
PS-GARCH-t & 1.29 & 4.83 & 0.66 & 0.147 & 4.43 & 3.6 & 2.75 & 4.16 & 2.64 \\
\hline \hline
\end{tabular}

Note: Footnote (1): $\mathrm{R}^{2}$ Values are from McAleer et. el. (2006).

The best performing models are the SI-EGARCH and SI-PGARCH models, which would lead to average daily capital charges of $7.97 \%$ and $8.04 \%$, respectively. With the exception of 
the Riskmetrics ${ }^{\mathrm{TM}}$ model, all SIVMs lead to lower daily capital charges than the corresponding PVMs suggesting that the penalties imposed under the Basel Accord may not be sufficiently severe, as Basel Accord tends to favor models which lead to an excessive number of violations (Ahmed; 2014). Furthermore, all the SIVMs which are estimated assuming a t-distribution lead to higher capital charges than the equivalent models estimated under a normal distribution. From a regulatory viewpoint, the portfolio model may be preferred as it is likely to lead to fewer bank failures, while banks are likely to favor the model which leads to the lowest costs. Although these results might seem to offer support for the use of these two SIVMs, it is important to note that the SI-EGARCH and SI-PGARCH models lead to 30 and 31 violations, respectively, larger than their t-distribution counterparts. Overall, the numbers of violations are considerably greater for the SIVMs than for PVMs (McAleer et. el.; 2006). The first, second, third and fourth highest ratio scores had gone to P-CCC-t, P-PS-GARCH-t, P-VARMAGARCH-t and P-EGARCH-t respectively while P-PGARCH-t and P-GJR-t were both at fifth position.

\section{Conclusion}

The results are interesting especially if we compare it with McAleer et el. (2006) and Sharma (2012). The portfolio approach was found to yield superior portfolio volatility forecasts based on the linear regression approach. SIVMs lead to an excessive number of violations, while the PVMs have too few violations. SIVMs led to lower daily capital charges based on the Basel Capital Accord penalties, as compared to PVMs. Finally, in SIVMs, the models which display correct conditional coverage led to higher capital charges than models which led to excessive violations.

These results seemed to suggest that the penalties imposed under the Basel Capital Accord may be too lenient, and tended to favor models that had an excessive number of violations, as well as models that were found to be sub-optimal based on various performance criteria. Overall, the 'PGARCH' and 'Riskmetrics ${ }^{\mathrm{TM}}$ ' are the most superior model while 'Std. Normal' is the least preferred models (in both) in SIVMs and PVMs respectively. Based on Number of Violations criteria, the PGARCH-t \& EGARCH-t are the most superior models and ARCH as least preferred one amongst SIVMs while 'Std. Normal' is the least preferred model and PSGARCH-t and VARMA-GARCH-t are most preferred models amongst PVMs.

\section{Disclaimer}

The research is meant for academic purposes only and authors or any affiliate organizations are not liable for any application of this research in practical settings.

\section{References}

Ahmed, A., (2014) How to Benefit from Basel III Recommendations to develop Risk Management Practices? Deloitte \& Touche, Middle East, April.

Al-Harbi, K. \& Al-Subhi, M., (2001) Application of the AHP in project management. International Journal of Project Management, 19, 19-27.

McAleer, M. and da Veiga, B., (2006) Single Index and Portfolio Models for Forecasting Value-at-Risk Thresholds. School of Economics and Commerce, University of Western Australia.

Anjum, S., (2013a) Risk Adjusted Business Intelligence Architecture for Cloud Computing for Banking Industry. In Proceedings of International Conference on Information \& Social Science (ISS2013), Nagoya, Japan, September. 
Anjum, S., (2013b) Algorithms for Predictive Classification in Data Mining: A Comparison of Evaluation Methodologies. Journal of Industrial and Intelligent Information (JIII), 1(2), June.

Anjum, S., (2014a) Backtesting VaR Violations, Be-ALAM Regression and Internal Models of Portfolio Variance Forecasting. Journal of Money Investment and Banking, Issue 29, September.

Anjum, S., (2014b) Composite Indicators for Data Mining: A New Framework for Assessment of Prediction Classifiers. Journal of Economics, Business \& Management, 2(1), February.

Anjum, S., (2014c) Systematic Risk Outliers and Beta Reliability in Emerging Economies: Estimation-Risk Reduction with AZAM Regression. Review of Integrative Business and Economics Research (RIBER), 3(1).

Anjum, S., (2014d) Quantification of Fiduciary Risks: Islamic Sources of Funds, NeoInstitutionalism and SARWAR Bank. Journal of Islamic Banking and Finance, 2(1), March.

Anjum, S., (2014e) Statistical Software and Regression Diagnostics Reporting with Fuzzy AHP Intelligent Zax (FAIZ). Lecture Notes in Software Engineering, 1(2).

Anjum, S., (2015a) Balance Sheet Structure, Asset Side Products and Shariah Financial Engineering: Risk Ranking of Banks. Proceedings of 2015 International Conference on Advanced Research in Business and Social Sciences (ICARBSS), 1, Kuala Lumpur, Malaysia.

Anjum, S., (2015b) Market Orientation, Balance Sheets and Risk Profile of Islamic Banks. International Journal of Economic Policy in Emerging Economies, Indersciences, 8(4), October.

Anjum, S., (2017a) Banking Automation with Sustainable Hedging for Information Risks: BASHIR Framework for Clouds Computing. Advanced Science Letters, American Scientific Publishers, USA, November.

Anjum, S., (2017b) Risk Magnification Framework for Clouds Computing Architects in Business Intelligence, Proceeding of International Conference in Information Education and Technology (ICIET 2017), Association of Computing Machinery (ACM), USA.

Anjum, S., (2018) Bank's Middle Office Analytics, Risk Modeling and Comparative Basel Regimes. International Journal of Monetary Economics and Finance, 11(4), October, 354 $-362,095746$.

Bhandari, K. G., (2010) Market Risk - Internal Model Approach, Indian Banks’ Association, 4th Annual summit, India.

Bonissone, P.P. (1988) Analytical Hierarchy Process. Website: www.rpi.edu/ bonisp/

Chaudhary, M. A. \& Anjum, S. (1996) Macroeconomic Policies and Management of Debt, Deficit, and Inflation in Pakistan. Pakistan Development Review. 35(4), Part II (winter), 773-786.

Dardac, N. \& Grigore A. (2011) Modeling the Market Risk in the Context of the Basel III Accord. Theoretical and Applied Economics. XVIII (11), 564, 5-20.

Huynh, T. L. D., Nasir, M. A., Nguyen, S. P., \& Duong, D. (2020) An assessment of contagion risks in the banking system using non-parametric and Copula approaches. Economic Analysis and Policy, 65, 105-116.

IBM., (2011) Banking Data Warehouse Support for the Basel II and Basel III Framework: Including Support for the Capital Adequacy Framework and Federal Financial Institutions Examination Council, BDW Release 8.4. Whitepaper

Kou, S., Peng, X. \& Heyde, C. C., (2012) External Risk Measures and Basel Accords. Mathematics of Operations Research, INFORM. 
Kramer, B. Kronbichler, D. van Welie, T. \& Putman, J., (2008) Comparing (Social) Objectives for Decision-Making in Housing Corporations. Applied Working Paper No. 2008-02 May, Ortec Finance Research Center (OFRC), Rotterdam.

Le, T. N. L., Nasir, M. A., \& Huynh, T. L. D. (2020) Capital requirements and banks performance under Basel-III: A comparative analysis of Australian and British banks. The Quarterly Review of Economics and Finance.

McAleer, M. \& Veiga, B., (2006) Single Index and Portfolio Models for Forecasting Valueat-Risk Thresholds. Research paper, School of Economics and Commerce. University of Western Australia.

Mehta, A., Neukirchen, M., Pfetsch S. \& Poppensieker, T., (2012) Managing market risk: Today and tomorrow. Working Papers on Risk, Number 32, McKinsey \& Co.

Ngo, T. T., Le, M. Q., \& Ngo, T. P. (2019) Incorporating risk into technical efficiency for Vietnam's and ASEAN banks. Journal of Asian Business and Economic Studies. 26(1), 216.

Pwc., (2012) A Closer look at US Basel III Regulatory Capital Regime and Market Risk Final Rule. Price Waterhouse Coopers ( $p w c$ ), USA.

Rowe, D. M. \& Holt, G. A. (2011) Modeling and Analyzing Market Risk Capital Requirements Under the Basel III Internal Models Approach with Kamakura Risk Manager. Kamakura Corporation, USA, February.

Shamim, F. \& Anjum, S. (2013) Technology Diffusion in Japanese Finance Industry: An Exploration. International Research Journal of Applied Finance, VI (12), December.

Shamim, F., Anjum S. \& Wakil, A. B., (2015) Banking Risk and Operating Efficiency Measures in the Era of IT. Accounting and Finance Research. Sciedu Press. 4 (1).

Sharma, M., (2012) Evaluation of Basel III revision of quantitative standards for implementation of internal models for market risk. IIMB Management Review, Indian Institute of Management Bangalore, 24, 234 - 244.

Stretton, C., (2011) Basel III - Market Risk. The Trading Book Series, Deloittee, Accessed Online (May 2014): www.deloitte.com/assets/Dcom-SouthAfrica

Sugiarto, S., \& Suroso, S. (2020) Innovation of impairment loss allowance model of Indonesian financial accounting standards 71. Journal of Asian Business and Economic Studies. Forthcoming. 